\title{
Perspectives
}

\section{Learning Culture through Ethnographic Inquiry: A Response to Roumiana Ilieva "Living with Ambiguity"}

Mari Haneda

In her article entitled "Living with Ambiguity: Toward Culture Exploration in Adult Second-Language Classrooms," Ilieva (2001) proposes taking a "culture exploration" approach in adult second language (L2) education. Underlying this approach is the view of language as social practice and of culture as fluid, interpretive, changing, lived, and internally diverse. It is, therefore, not the teaching of uncontested cultural facts that is promoted in this approach, but the process of joint exploration of, and critical reflection on, students' lived cross-cultural experiences. Briefly, in this approach students act as participant observers in and outside the classroom, share their ethnographic accounts with their classmates for joint reflection, identify any perceived problems, and collaboratively construct strategies to deal with the particular situations under discussion.

Ilieva argues for the importance of students' agency in taking ownership of their experiences in the mainstream culture so as to act in the world effectively. I am very much in agreement with her advocacy stance. In this response article, I wish to expand on two issues that were touched on in the original article. First, what is involved in student ethnography and second, the complexity of our cultural lives.

\section{L2 Adults as Ethnographers}

Through one's primary socialization, one develops a repertoire of how to talk and act as a community member. One acquires a set of practices that enable one to participate effectively in a particular social world (Schieffelin, 1990). One is socialized into particular cultural practices over time and gradually expands one's repertoire, the linguistic and cultural resources for various course of action. Adult L2 students, who have already developed repertoires in their home countries, face the task of socializing themselves into new sets of rules and norms. As an adult immigrant to Canada myself, I empathize with the enormity of their task, that of appropriating social practices in the mainstream culture and of reinventing one's identity and developing one's own voice in relation to the prevailing conditions. 
To facilitate this transition, Ilieva (2001) suggests that students act as participant observers and, with their classmates, explore their experiences in the mainstream culture:

By paying close attention to everyday interaction in observed social settings and by keeping records of what they have seen and their thoughts and feelings in these situations, students will be equipped with material to explore in classroom discussion with a view to voicing their experiences, searching for possible reasons behind those experiences, and starting to recognize the symbolic and contextual meaning of everyday verbal and nonverbal behavior. (p. 10)

In this way students become informed about the social practices in the target culture on the basis of their new experiences and more aware of the cultural beliefs and values that they already espouse. They are then in a position to develop their own strategies to deal with the particular situations under discussion. I find this orientation to curriculum empowering, because it offers the possibility for students to enact the mode of thinking nurtured in the classroom discussion in their future lives. I am very much in agreement.

I wish to address here not a gap in Ilieva's writing, but rather a potential issue with respect to students conducting ethnography. Borrowing Erickson's (1996) terms, the issue can be described as how to balance Adam's and Eve's tasks. "Adam's work" is to describe others and their points of view in observed social practices. However, it has certain limitations because "the so-called 'participant observer' is only minimally participating, and is mostly outside the social gravity within which the 'observed' live" (p. 7). To compensate for this problem, ethnographers need to take on what Erickson calls "Eve's task," that is to say, moving from the role of a participant observer to that of an "observant participant" for whom research is personal and relational. Although this dichotomy may be an oversimplification and have an unfortunate sexist connotation, I nonetheless use these terms in my discussion to make my point clear. Adam's and Eve's tasks are best understood as being situated at the opposite ends of the continuum implied by the widely used fourfold typology of the role of participant observer: complete observer, observer as participant, participant as observer, and complete participant (Atkinson \& Hammersely, 1994).

Ilieva addresses Adam's and Eve's tasks in two stages: students' ethnographic work and classroom discussion. The first stage involves assisting students to develop the perspectives characteristic of participant observers in the classroom and later in their fieldwork. She explains this in terms of duality of purpose, "engaging in the activities appropriate for the situation and at the same time observing oneself and others in the situation; and record keeping: keeping a detailed record of observations, experiences, and feelings in the situation" (p. 10). The second step involves assisting students to engage in classroom dialogue through the five-step questioning strategy: 
(a) What do/did you see? (b) What is/was happening? (c) How does this relate to your lives? (d) How do you react to that? Is this a problem for you? and (e) How do you plan to deal with situations like that? This progression is well thought out. The first two steps culminate in students' producing ethnographic accounts of observed situations in the target culture. As Ilieva rightly points out, the descriptive observation is not neutral because observers inescapably describe events from their own viewpoints. The next three steps involve an increasing degree of analysis of the situations under discussion in relation to students' lives. In explaining the fourth step, Ilieva notes:

In the course of the discussion, students elaborate on the nature of their experience and on the sense of culture shock they felt at the observation or that they feel now in the classroom while discovering possible meanings of the observed situation. They also discuss their own verbal and nonverbal behavior in the situations and explore the approaches they have taken to manage or express this sense of culture shock. (pp. 11-12)

Judging from the second half of this description, students appear to be expected to act as "observant participants" from step 1. Thus the culture exploration approach appears to lean toward Eve's task. There is nothing controversial about this. In essence it embodies good action research.

However, it leads me to wonder how teachers can best assist students to balance Adam's and Eve's tasks as ethnographers and to what extent students might benefit from acting as "participant observer" of a situation in which they are not centrally involved (being Adam). Ethnography, like other forms of qualitative research, is built on a recursive process of going back and forth between Eve's and Adam's tasks. At the risk of oversimplification, it appears to me that one deals with cross-cultural encounters in a sequence of being Eve-Adam-Eve (although this is a recursive process). That is, one first lives cross-cultural encounters, noticing things that are personally significant; therefore, this kind of observing is not necessarily systematic (being Eve). One next goes through a stage where one self-consciously performs a more systematic observation of the phenomenon in question (being Adam). Finally, one loops back to being a better-informed Eve, making sense of one's experiences and developing strategies to deal with any problems that one has encountered or foresees.

Given this looping action, I wonder whether students might benefit from honing their skills as Adam before they embark on Eve's task? If so, how might Adam's task be realized in L2 classrooms? One suggestion would be to use videotapes of cultural encounters that are appropriate for particular groups of student. After viewing the videotape, students can engage in the above-mentioned five-step question sequence with their classmates. Using the scenes depicted in the videotape as building blocks and interpreting features of participants' behaviors and the settings (e.g., actual words ex- 
changed, nonverbal behaviors, intonation, pronunciation), teachers can also model for the students the process of triangulation. The next step might be for students to observe others' actions in real-life settings of personal importance or choice (or other settings that teachers deem appropriate). Based on the reporting of their ethnographic accounts, teachers could use the same questioning sequence to prepare students for a more fully fledged version of the culture exploration approach.

\section{The Complexity of Our Cultural lives}

Ilieva argues for an approach to the exploration of culture that "facilitate[s] learners' gaining awareness of humans as inherently cultural beings" (p. 9) and "allow[s] the development of skills to investigate culture, question cultural presuppositions, think critically with respect to cultural norms, and learn to live with the ambiguity inherent in cross-cultural encounters" (p. 2). She stresses the importance of classroom dialogue following ethnographic fieldwork, which functions as "the means by which the students' experience could be named and translated into a voice" (p. 11 ). It is through dialogic inquiry that students explore the process of naming their experiences, "develop an intercultural or third voice" and "engage in culture creation" (p. 12). Underscoring this approach is a pedagogical orientation toward empowerment and an attention to aspects of culture that have not been highlighted in traditional culture teaching, namely, history, variation, and change.

In this section, drawing on Vygotsky's (1978) "genetic" approach, I wish to reflect on these issues of history, variation, change, and empowerment: threads that run through the whole of Ilieva's article. Briefly, Vygotsky argued that current behavior can only be adequately explained in relation to its genesis, that is to say, its origin and the history of its development to the present; hence the genetic approach. Of the four levels of genetic analysis proposed by Vygotsky, I draw on the following three genetic domains: sociocultural history, ontogenesis, and microgenesis

The culture exploration approach is premised on the recognition of humans as culturally positioned subjects who have appropriated social practices that are deeply anchored in layers of history. These practices, which represent particular modes of thinking, feeling, saying, and acting in the world, have been shaped by the sociopolitical histories of both the multiple diverse communities in which students have participated as members and the nation state in which these communities are embedded. Although students who share the same first language and country of origin may operate in similar frameworks, their unique life histories make them distinct from their compatriots. Every individual has developed his or her own personal interpretive framework through membership in a particular set of communities: family, work, religion, sport, and so on. Considered thus, the sociopolitical histories of the multiple communities to which students have 
belonged are coalesced in individuals' repertories of practices, beliefs, and values.

In the cultural exploration approach, emphasis is placed on students' developing self-awareness of the cultural and historical influences on their personal development. Having their classmates as critical commentators on their interpretations of observed events, students are confronted with diverse viewpoints expressed by their classmates and pushed to examine their own cultural assumptions critically (part of being a historical, cultural self). In collaboration with their classmates, students engage in the challenging task of uncovering their espoused beliefs and values. As they sharpen their analytical skills through classroom dialogue, they begin to unveil the historical layers of their own lives. With this awareness of historical self, they are in a position to participate in the creation of a different culture in collaboration with others (including their classmates and members of the target culture).

Creation of a "a culture of the third kind" (Kramsh, 1993) is dependent on possibilities of change, which occurs not only in the three genetic domains described above, but also as a result of external and interpersonal influences. As I argue above, change occurs not only at the level of individual lives, but also at the levels of local communities and the larger society. Consider, for example, the large urban centers in North America where changes in demography and sociopolitical climate are reshaping and redefining the practices of their constituent communities, thereby influencing individuals' practices. Change can also result from interpersonal encounters such as those between students. The cultural exploration approach specifically addresses change in individuals. Students are encouraged to take a proactive role in creating a culture of the third kind where they express their meanings "without being hostage to the meanings of either their own or the target speech communities" (pp. 13-14). In so doing they are able not only to act effectively to achieve their own personal goals, but also to contribute significantly to changing the local social practices in which they take part.

As noted above, the cultural exploration approach places most emphasis on individuals' experiences in the target culture based on which they explore cultural meaning in relation to their ontogenetic trajectories. According to Ilieva, empowerment results when students take a proactive stance in naming, unnaming, and renaming their experiences in a new culture. To do so, they need to adopt a view of culture as constantly undergoing change and to recognize themselves as cultural and historical beings. On this basis they are in a position to claim their experiences. In the light of the foregoing arguments, it seems clear that in construing culture as historical, changing, and displaying.internal diversity, it is important to attend to all three genetic levels of development and to see individuals as multiply historically situated, as well as distinctly unique and potential agents of change. 
However, adopting the view of culture and individuals as described above also creates a sense of uncertainty both for teachers and students. As a guide for students' cultural exploration, $\mathrm{L} 2$ teachers need to ask themselves the same set of questions that they ask their students to consider. It is only through critical reflection on their own cultural assumptions that teachers are in a position to provide empathetic support to students. To act as facilitators of this process, teachers themselves need to act as learners who explore culture together with their students in the classroom and with colleagues outside class.

Linking this argument back to my discussion of Adam's and Eve's tasks in student ethnography, I suggest that an enactment of the transformative process described above requires attention to both these tasks. Eve's personal, relational thinking is critical in taking ownership of one's experiences. At the same time, by acting as Adam, who observes social practices systematically and objectively, students can analyze and assess observed situations without jumping to conclusions based on their own espoused views. By engaging fully and recursively in Adam's and Eve's tasks, students can be empowered to promote change more deliberately and systematically.

In essence, the cultural exploration approach is emancipating and actionoriented: good participatory action research. It reminds us that culture is a verb (process, action) as well as a noun (a list of unquestioned facts about cultural practices). It is in the doing, particularly the acting in concert with other community members in specific instances of learning, work, and play, that the abstract notion of culture comes to life and is lived as it is enacted in practice.

\section{The Author}

Mari Haneda has recently completed a doctorate in the Second Language Education Program at the Ontario Institute for Studies in Education of the University of Toronto (OISE/UT). She is currently an SSHRC postdoctoral fellow at the University of California, Santa Cruz. Her research interests include classroom-based research in second-language acquisition, L2 literacy, discourse analysis, and ethnographic research approaches to L2 learning and teaching.

\section{References}

Atkinson, P., \& Hammersley, M. (1994). Ethnography and participant observation. In N.

Denzin \& Y. Lincoln (Eds.), Handbook for qualitative research (pp. 248-261). Thousand Oaks, CA: Sage.

Erickson, F. (1996). On the evolution of qualitative approaches in educational research: From Adam's task to Eve's. Australian Educational Researcher, 23(2), 1-15.

Ilieva, R. (2001). Living with ambiguity: Toward culture exploration in adult second-language classrooms. TESL Canada Journal, 19(1), 1-16.

Kramsch, C. (1993). Context and culture in language teaching. Oxford, UK: Oxford University Press.

Schieffelin, B. (1990). The give and take of everyday life: Language socialization of Kalui children.

New York: Cambridge University Press.

Vygotsky, L. (1978). Mind in society: The development of higher psychological processes. Cambridge, MA: Harvard University Press. 